\title{
Endovascular treatment of abdominal aortic
} \section{aneurysms: initial experience and short and mid- term results}

\author{
Tratamento endovascular dos aneurismas de aorta abdominal: experiência inicial e resultados a curto \\ e médio prazo
}

Eduardo Keller SAADI ${ }^{1}$, Fernando GASTALDO ${ }^{2}$, Luiz Henrique DUSSIN ${ }^{3}$, Alcides José ZAGO ${ }^{4}$, Gilberto BARBOSA $^{5}$, Leandro de MOURA ${ }^{6}$

RBCCV 44205-819

\section{Abstract}

Objective: The purpose of this study is to present the short and medium-term results of the endovascular treatment of abdominal aortic aneurysms (AAAs). This is an initial experience of a multidisciplinary team.

Method: Between July 2003 and October 2005, 42 patients (25 of whom suffered from AAAs) were treated with endovascular therapy for aortic diseases. The mean patient age was $74 \pm 10.2$ years with $92 \%$ men. The endovascular procedures were performed by a multidisciplinary team in the Hospital de Clínicas de Porto Alegre and Hospital Luterano (ULBRA). In twenty-four of the AAA patients, bifurcated grafts were used and only one had a straight graft. In all patients the procedure was carried out by femoral artery dissection in a catheterization laboratory. There was no need to convert to open repair.

Results: There were no operative or postoperative deaths. The survival rate free from re-interventions is $96 \%$ after
1 - Ph.D. Professor of the Medicine School UFRGS and ULBRA Cardiovascular surgeon

2 - Specialist in interventionist radiology. Interventionist radiologist of the Hospital de Clínicas de Porto Alegre

3 - Master in Medicine. cardiovascular surgeon of the Hospital de Clínicas de Porto Alegre

4 - Ph.D. Professor of the Medicine School UFRGS and ULBRA interventionist cardiologist

5 - Specialist in cardiovascular surgery. Professor of the Medicine School UFRGS cardiovascular surgeon

6 - Specialist in cardiovascular surgery Masters in medicine UFRGS

Work carried out in Hospital de Clínicas de Porto Alegre (HCPA)/UFRGS and Universidade Luterana do Brasil (ULBRA), Porto Alegre, RS.

Correspondence address:

Dr. Eduardo Keller Saadi. Rua Pedro Weingartner, 125/801. Porto Alegre, RS, Brazil. CEP 90430-140. Phone (51) 21018342.

E-mail: esaadi@terra.com.br two years and three months. One (4\%) patient needed a new endovascular procedure for a type I endoleak one year after, and three extensions were used successfully. Two other patients needed femoro-femoral bypasses, one at the same time as the endovascular procedure and the other one 24 hours later because of lower limb ischemia.

Conclusion: The endovascular treatment of AAAs represents a new less invasive alternative to conventional surgery, especially for high risk patients. Further prospective and randomized studies to evaluate the long term outcomes are needed. Excellent results in the short and medium-terms can be obtained by multidisciplinary teams in our country.

Descriptors: Aortic aneurysm. Prostheses and implants. Stents.
Article received in November, 2005 Article accepted in March, 2006 


\section{Resumo}

Objetivo: $O$ estudo visa a apresentar os resultados a curto e médio prazo do tratamento endovascular dos aneurismas de aorta abdominal (AAA). Trata-se de uma experiência inicial com uma equipe multidisciplinar.

Método: No período entre julho de 2003 e outubro de 2005, 42 pacientes foram submetidos a tratamento endovascular de doenças da aorta, sendo 25 por aneurismas de aorta abdominal (AAA). A idade média foi de $74 \pm \mathbf{1 0 , 2}$ anos e $92 \%$ dos pacientes eram do sexo masculino. Os procedimentos foram realizados por uma equipe multidisciplinar, no Hospital de Clínicas de Porto Alegre e Hospital Luterano (ULBRA). Vinte e quatro pacientes foram submetidos à colocação de endoprótese bifurcada e um, reta. Em todos os pacientes, o procedimento foi realizado por dissecção das artérias femorais, em laboratório de hemodinâmica. Em nenhum caso houve necessidade de conversão para cirurgia aberta.

Resultados: Não houve óbito nesta série. Até 2 anos e 3 meses de acompanhamento, todos os pacientes estão vivos e $24(96 \%)$ livres de reintervenção relacionada ao aneurisma.

\section{INTRODUCTION}

Interest in the development of minimally invasive techniques for surgery has grown very much over the last few years. The 1990s presented a technological revolution in the treatment of aortic diseases. In 1991, Parodi et al. [1] published the first case of abdominal aortic aneurysm (AAA) treated by endoprosthesis via the femoral artery.

The conventional surgical treatment of AAAs requires laparotomy and replacement of the abdominal aorta by a prosthesis. With endovascular treatment, laparotomy is avoided and, by incisions in inguinal area, the endoprosthesis may be implanted in a less invasive procedure. The endoprosthesis is retrogradely directed along a guide-wire through the common femoral artery, via the iliac arteries to the abdominal aorta. Once correctly positioned, it is immediately released below the renal arteries. Blood loss is much less than conventional surgery, the aorta does not need to be clamped and patient recovery is faster $[2,3]$. Careful selection of patients based on reliable imaging methods including computed tomography (CT) must always be employed, taking into consideration several factors and a rigid protocol of measurements (Figure 1).

Several prospective and randomized studies are being conduced in order to compare the conventional with endovascular technique. Two already published studies, the EVAR 1 [2] and the DREAM [3] trials show a trend of lower surgical mortality rates, even in low risk patients, offering a viable alternative with less morbidity than conventional surgery.
Um (4\%) paciente necessitou novo procedimento endovascular por vazamento tipo I, um ano após, sendo colocadas três extensões. Dois outros necessitaram derivação femoro-femoral cruzada, um no momento do procedimento endovascular e o outro, 24 horas após, por apresentar isquemia de membro inferior direito.

Conclusão: O tratamento endovascular dos AAA representa uma nova alternativa à cirurgia convencional, menos invasiva, principalmente para pacientes com alto risco cirúrgico. Como o procedimento é relativamente novo, estudos prospectivos e randomizados são necessários para avaliar resultados a longo prazo. Excelentes resultados a curto e médio prazo podem ser obtidos em nosso meio.

Descritores: Aneurismas aórtico. Próteses e implantes. Contenedores.

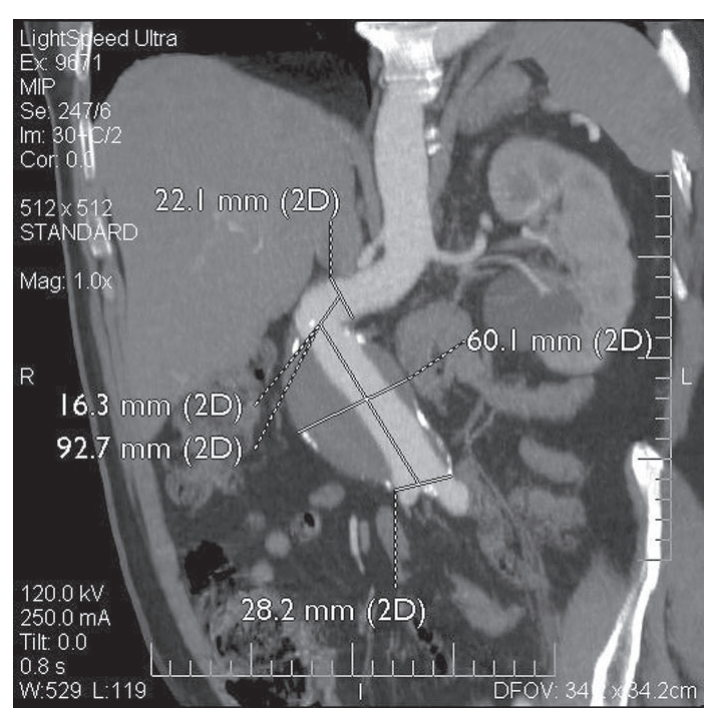

Fig. 1 -Some measurements in the computed tomography in the preoperative evaluation of a patient with AAA and angled neck

Another point of discussion is which professional should perform the procedure, as there is overlapping among interventionist cardiology, interventionist radiology, vascular surgery and cardiovascular surgery. The learning curve of surgeons to perform procedures by catheter is sometimes long. In our institution, we have set up a team with interventionist cardiologist, vascular radiologist, anesthetist with experience in aortic surgery and cardiovascular 
surgeons.

The objective of this work is to present the facts and the short and medium-term results of endovascular procedures for AAAs performed by this multidisciplinary team, coordinated by a cardiovascular surgeon.

\section{METHOD}

Between July 2003 and October 2005, 42 patients were submitted to endovascular treatment for aortic diseases in the Hospital de Clínicas de Porto Alegre (HCPA) and Hospital Luterano (ULBRA), both in Brazil. Of the 42 patients, 17 were cases of aneurysms or thoracic aortic dissections and 25 of abdominal aortic aneurysms (AAAs); this latter group is the series studied in the current work. All patients signed written informed consent forms. Three brands of endoprostheses were utilized: at the start of the investigation, Braile stainless steel with polyester (two cases) and subsequently Braile nitinol with polyester (10 cases) endoprostheses were used. Medtronic nitinol with polyester (12 cases) and Gore Tex nitinol with PTFE (one case) were also employed. In total twenty-four bifurcated and one straight endoprostheses were implanted. The criterion for the surgical indication of AAAs was a diameter greater than $5 \mathrm{~cm}$. Twenty-two $(88 \%)$ of the patients were asymptomatic, two (8\%) had expanding aneurysms (symptomatic) and one $(4 \%)$ the aneurysm was ruptured. Most of the patients presented with some contraindications for conventional surgery and others, after an explanation of the therapeutic choices, opted for endovascular treatment. All patients were submitted to tomography in the preoperative period, for careful selection using the following criteria:

- Distance $>1.5 \mathrm{~cm}$ between lowest renal artery and the start of the AAA;

- Absence of curvature $>90$ degree of proximal neck;

- Absence of significant calcification in the proximal neck;

- Absence of significant obstruction in the aortic-iliac region;

- Femoral and iliac arteries with diameters $>7 \mathrm{~mm}$ (for $22 \mathrm{~F}$ delivery catheter).

Additionally, all patients observed the postoperative followup protocol, which included computed tomography in the first month, at six months and thereafter each 12 months if there was no evidence of endoleaks.

Twenty-three $(92 \%)$ patients were men and the mean age was $74 \pm 10.2$ years. All patients were submitted to the procedure of femoral artery dissection in the hemodynamics laboratory, with anesthesia to the rachidian nerve. One (4\%) patient presented with a ruptured AAA and the other patients underwent elective surgeries. No patient needed conversion to laparotomy and the mean hospital stay was 4 days (range from 2 to 7 days). The patients stayed during one night in the heart intensive care unit and in the following morning were transferred to the wards.

\section{RESULTS}

There were no deaths in the trans- and post-operative periods. Two $(8 \%)$ patients needed crossed femoro-femoral derivations, which were successful performed without ischemic sequels. For one of these patients it was in the same procedure due to dissection of a plaque and occlusion of iliac artery and for the other, it was 24 hours after, due to ischemia of the lower limb caused by iliac artery occlusion. Both patients evolved without ischemic sequels. All patients are alive after a follow-up time of between 2 and 27 months. One patient presented with a type I endoleak; he was successfully submitted to another endovascular intervention with the placement of three extensions (one proximal and two distal) one year after the initial procedure. Twenty-four (96\%) patients are alive and free from new interventions in up to 27 months of follow-up (Figure 2). Another patient presented with a type II endoleak, with a slight retrograde filling via the lumbar arteries; the patient is being accompanied by means of serial tomographies, but has not shown any increase in the aneurysm. All patients are being submitted to periodical evaluations by computed tomography, with the first evaluation one month after the procedure then after 6 months and thereafter once per year.

\section{DISCUSSION}

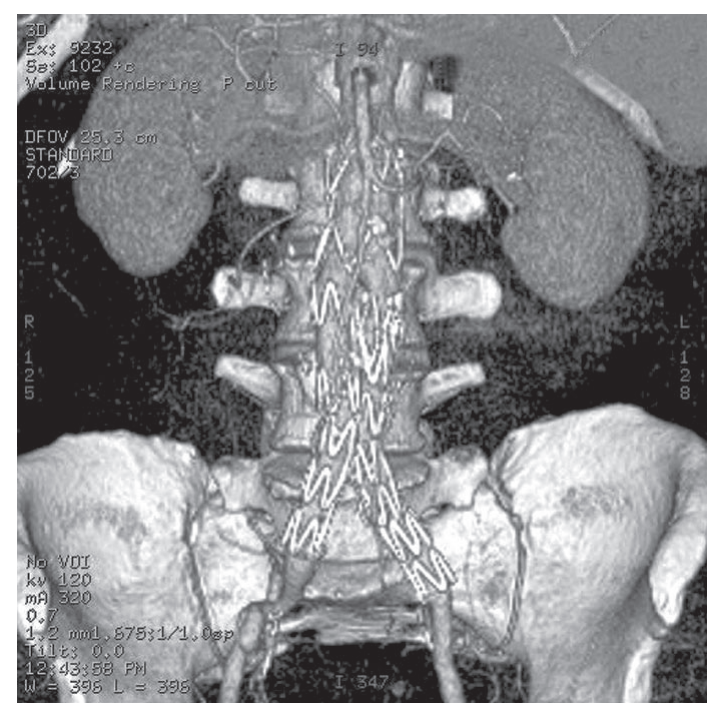

Fig. 2 - Control angiotomography of a patient submitted to bifurcated endoprosthesis implantation for AAA repair 
Not all patients with AAAs with indications for intervention are candidates for endovascular procedures and, in reality the adequate selection of patients is the most important factor for success in treatment [4-9]. The main criterion of selection relates to the anatomy of the aortic, iliac and femoral system (5).

Computed tomography is currently considered the best examination for the evaluation of patients with AAAs in order to study the possibility of endovascular repair [810]. The images are achieved with iodated contrast and performed with 2- and 3-dimentional reconstruction with all the necessary measurements. It is also the preferential method and the most reliable for the post-implant follow-up and to identify endoleaks (Figures 3 and 4).

In respect to the materials, several have been tested, but most endoprostheses are currently manufactured from metallic alloys (nitinol or stainless steel) and covered with fabric (PTFE or polyester). Endoprostheses have been designed to be delivered in the arterial system utilizing guide-wires and delivery systems so that they can be introduced via the femoral and iliac arteries without causing injury. Ideally, the material must be strong enough to avoid

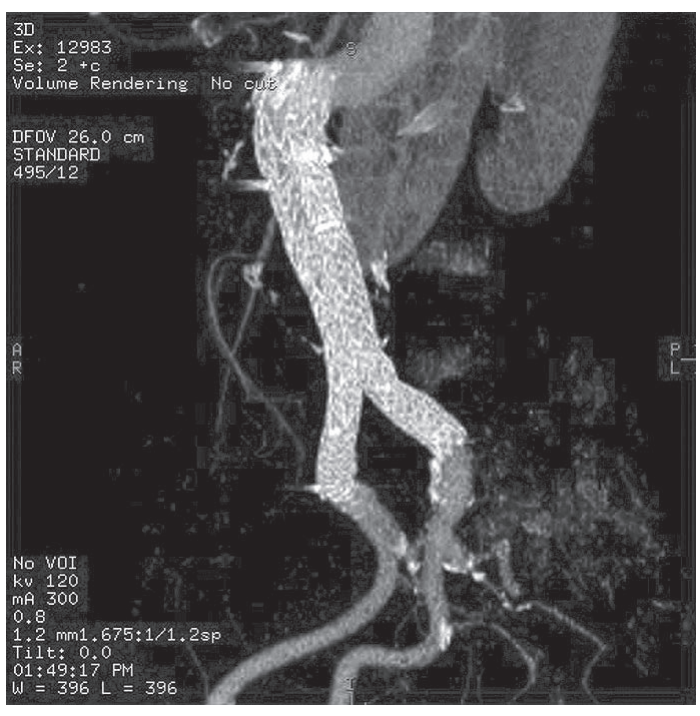

Fig. 3 - Control computed tomography after endovascular repair with bifurcated endoprosthesis in a patient with AAA and angled colon deterioration with time and at the same time, sufficiently thin and supple to go into delivery catheters. Most are selfexpanding and are anchored to the aorta by outward force. They may be placed using a balloon; some apparatuses have hooks or clamps for anchoring in order to reduce the possibility of migration. Some endoprostheses have a small uncovered proximal segment, called the free-flow section, which is to anchor the stent over the renal arteries, increasing the length of contact with the proximal aorta in AAAs with short necks [8].

At hospital release, the patients need to be accompanied with periodical imaging methods [2, 4, 6, 11-13]. Computed tomography (CT) should be performed 30 days and again 6 months after the procedure and thereafter one time per year. Aortic Doppler echocardiography may be performed in this period and, if there is any suspicion of endoleak, computed tomography is required. When there is no possibility of performing computed tomography (allergy to the contrast or renal insufficiency), magnetic nuclear resonance must be used. We must be aware about the possibility of the migration of stents, occlusion of branches and endoleaks. Endoleaks, which are the most frequent complication of this procedure [4], are classified in four types:

\section{Re-intervention free survival}

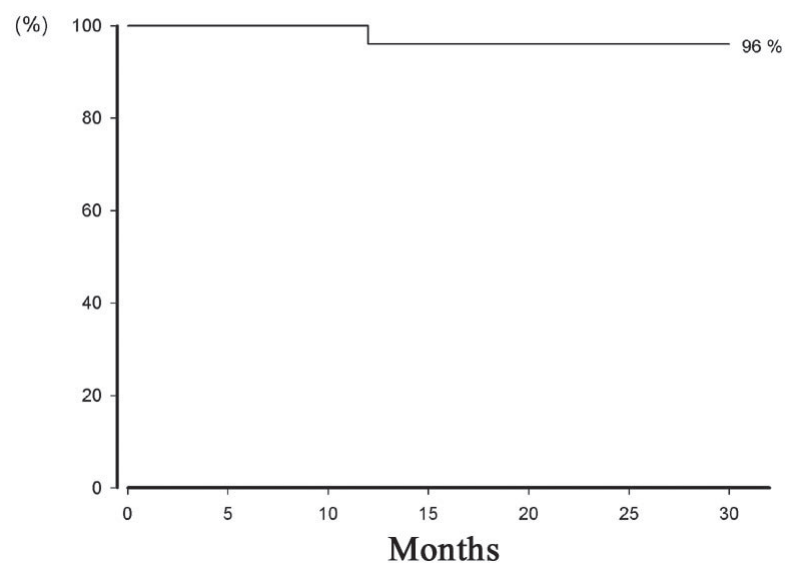

Fig. 4-Re-intervention free survival curve related to endovascular procedures over up to 27 months 
- Type I - Proximal (aorta) or distal (iliac arteries) endoleaks in the region of the anchoring of the graft in the arterial wall;

- Type II- Retrograde flow into the aneurysmatic sac via the inferior mesenteric or lumbar arteries or other collateral routes;

- Type III- Structural problems of the endoprostheses (fractures of the metallic structure, disconnection or rupture of the fabric);

- Type IV- Porosity of the tissue (common in the immediate post-implantation period).

Recently another type (Type V) was described, where endoleaks are not identified, but the aneurysm continues to increase, probably due to transmission of pressure, also called endotension.

The Type I and III endoleaks, in general, require repair, which can be performed by another endovascular repair. In our study, two (8\%) patients presented with endoleaks. One of them presented with a Type II endoleak (via lumbar arteries) and is being accompanied with serial tomographies, without evidence of any increases in the size of the AAA. Another patient presented proximal and distal Type I endoleak one year after implantation and was successfully submitted to another endovascular repair, in which three extensions were utilized: a short proximal extension with free-flow and two distal extensions (one in each iliac artery).

There is a greater necessity to perform re-interventions in patients submitted to endovascular treatment compared to open surgery $[4,7-9,14]$. However, the evolution in terms of materials used has been great over the last few years. Initially, endoprostheses were individually crafted for each individual case but more recently they are being produced by specialized companies and subjected to many in vitro tests.

In respect to the discussion on which professional should perform the procedure, we think that, independently of the specialty, the physician must have a profound knowledge of aortic diseases and be technically trained to perform the procedure. The Brazilian experience with the group from the Paulista Medical School gives us a great insight on how this model can be successful structured $[10,14,15]$. There is no doubt that the training of the cardiovascular surgeon in techniques of catheterism is different from the training in conventional surgery. Even so, the learning curve is not short and the initial results may be bad. We decided to form a multidisciplinary team (interventionalist cardiologist, vascular radiologist and anesthetist trained in aortic surgery), coordinated by a cardiovascular surgeon with the aim of trying to reduce the complications at the beginning. We believe that, for at least the first 10 to 15 endoprostheses implanted, the presence of the radiologist or interventionist cardiologist was important to facilitate or reduce the time of the procedure, mainly by helping to correctly place the stent when it was released and in the catheterism of contralateral branches. Currently, only one of the two professionals is present during the procedure and frequently, there is no necessity of participating. We also have aortic out-clinics for pre-procedure evaluation and follow-up consultations in the postoperative period.

There are some studies that compare the conventional surgical treatment with endovascular treatment in AAA. Two are still being prepared: the OVER (American study) and ACE (French study) trials. Other studies have already been published including the EVAR 1 (English study) [2] that demonstrated a significantly lower mortality rate in patients who were submitted to the endovascular treatment than in patients who were submitted to the open surgery $(1.6 \%$ x $4.6 \%$ - p-value $=0.007)$ and the DREAM multicentric Dutch trial [3], which also demonstrated a tendency of less operative mortality (over the first 30 postoperative days) with the endovascular procedure when compared with open surgery. In our series, we did not have any deaths during the procedure or within a follow-up period of up to 27 months.

However, this advantage in respect to the operative mortality is lost with time. A follow-up of 2 and 4 years in the DREAM [11] and EVAR $1[12,13]$ studies demonstrates a late mortality that is similar in both groups. It is interesting to observe that the majority of the medium-term deaths are not related to aneurysm rupture but to other causes such as infarction, strokes and cancer. These data only reinforce the diffuse characteristic and the involvement of different organs in the atherosclerotic process. One possible explanation of this fact is that patients submitted to open surgery present with complications related to atherosclerosis during hospitalization due to the great stress that they are submitted to, because of the scale of the procedure, whilst in the group submitted to endovascular treatment, the stress was much less during the procedure and the complications in other organs and systems appear in the postoperative followup period. It is important to highlight that in these series, less than $50 \%$ of the patients were submitted to the current recommendations of secondary prevention with antiplatelet adhesive agents, beta-blockers and statins $[11,13]$. In our study, there were no medium-term deaths, over a maximum follow-up time of 27 months and all patients were submitted to a rigid protocol of secondary prevention. Curiously, it was also demonstrated that patients without conditions for open surgery and who were randomized for endoprosthesis or clinical treatment also presented results similar to the survival curves over the medium-term postoperative period [12]. Studies with longer follow-up periods and larger numbers of patietns are required to present more data on 
long-term results with endoprostheses.

\section{CONCLUSION}

The endovascular treatment of aortic diseases represents a new less-invasive alternative to conventional surgery; mainly for high-risk surgical patients. As the procedure is relatively new (14 years), prospective and randomized studies are necessary to evaluate the long-term results. In the short and medium terms excellent results may be obtained with the formation of a multidisciplinary team coordinated by a cardiovascular surgeon.

\section{REFERENCES}

1. Parodi JC, Palmaz J, Barone HD. Transfemoral intraluminal graft implantation for abdominal aortic aneurysms. Ann Vasc Surg. 1991;5(6):491-9.

2. Greenhalgh RM, Brown LC, Kwong GP, Powell JT, Thompson SG. The EVAR 1 participants. Comparison of endovascular aneurysm repair with open repair in patients with abdominal aortic aneurysm (EVAR trial 1);30 day operative mortality results: randomized controlled trial. Lancet. 2004;364(9437):843-8.

3. Prinssen M, Verhoeven EL, Buth J, Cuypers PW, van Sambeek MR, Balm R et al. The DREAM participants. A randomized trial comparing conventional and endovascular repair of abdominal aortic aneurysms. N Engl J Med. 2004;351(16):1607-18.

4. Harris PL, Buth J, Miahle C, Myhre HO, Norgren L. The need for clinical trials of endovascular abdominal aortic aneurysm stent-graft repair. The EUROSTAR project. European collaborators on Stent-graft techniques for abdominal aneurysm repair. J Endovasc Surg. 1997;4(1):72-9.

5. Sternbergh WC III, Carter G, York JW, Yoselevitz M, Money
SR. Aortic neck angulation predicts adverse outcome with endovascular abdominal aortic aneurysm repair. J Vasc Surg. 2002;35(3):482-6.

6. Stanley BM, Semmens JB, Mai Q, Goodman MA, Hartley DE, Wilkinson $\mathrm{C}$ et al. Evaluation of patient selection guidelines for endoluminal AAA repair with Zenith stent-graft: the Australian experience. J Endovasc Ther. 2001;8(5):457-64.

7. Parodi JC. Endovascular repair of abdominal aortic aneurysms and other arterial lesions. J Vasc Surg. 1995;21(4):549-57.

8. May J, White GH. Endovascular treatment of aortic aneurysms. In: Rutherford R, ed. Vascular surgery. 5th ed. Philadelphia: WB Saunders;1999. p.1281-95.

9. Dake MD, Miller DC, Semba CP, Mitchell RS, Walker PJ, Liddell RP. Transluminal placement of endovascular stent-grafts for the treatment of descending thoracic aortic aneurysms. N Engl J Med. 1994;331(26):1729-34.

10. Palma JH, de Souza JA, Rodrigues Alves CM, Carvalho AC, Buffolo E. Self-expandable aortic stent-grafts for treatment of descending aortic dissections. Ann Thorac Surg. 2002;73(4):1138-42.

11. Blankensteijn JD, de Jong SE, Prinssen M, van der Ham AC, Buth J, van Sterkenburg SM et al. Dutch Randomized Endovascular Aneurysm Management (DREAM) Trial Group. Two-year outcomes after conventional or endovascular repair of abdominal aortic aneurysms. N Engl J Med. 2005;352(23):2398-405.

12. EVAR Trial participants. Endovascular aneurysm repair and outcome in patients unfit for open repair of abdominal aortic aneurysm (EVAR 2 Trial): randomized controlled trial. Lancet. 2005;365(9478):2187-92.

13. EVAR Trial participants. Endovascular aneurysm repair versus open repair in patients with abdominal aortic aneurysms (EVAR 1 Trial): Randomized controlled trial. Lancet. 2005;365(9478):2179-86.

14. Palma JH, Sampaio AM, Miranda F, Rodrigues Alves CM, Souza JA, Buffolo E. A change in the treatment of abdominal aortic aneurysms. Arq Bras Cardiol. 2003;81(5):518-25.

15. Palma JH, Miranda F, Gasques AR, Alves CM, de Souza JA, Buffolo E. Treatment of thoracoabdominal aneurysm with self-expandable aortic stent-grafts. Ann Thorac Surg. 2002;74(5):1685-7. 